\title{
Shape Optimization of a Wooden Baseball Bat Using Parametric Modeling and Genetic Algorithms
}

\author{
Mohammad Sadegh Mazloomi ${ }^{1,2, *(1)}$ and Philip D. Evans ${ }^{1}$ \\ 1 Centre for Advanced Wood Processing, Department of Wood Science, University of British Columbia, \\ Vancouver, BC V6T 1Z4, Canada; phil.evans@ubc.ca \\ 2 FPInnovations, 2665 East Mall, Vancouver, BC V6T 1Z4, Canada \\ * Correspondence: Mohammad-sadegh.mazloomi@fpinnovations.ca; Tel.: +1-604-222-5736
}

Citation: Mazloomi, M.S.; Evans, P.D. Shape Optimization of a Wooden Baseball Bat Using Parametric Modeling and Genetic Algorithms. AI 2021, 2, 381-393. https://doi.org/ $10.3390 /$ ai2030024

Academic Editor: AMM Sharif Ullah

Received: 18 May 2021

Accepted: 19 August 2021

Published: 22 August 2021

Publisher's Note: MDPI stays neutral with regard to jurisdictional claims in published maps and institutional affiliations.

Copyright: (c) 2021 by the authors. Licensee MDPI, Basel, Switzerland. This article is an open access article distributed under the terms and conditions of the Creative Commons Attribution (CC BY) license (https:// creativecommons.org/licenses/by/ $4.0 /)$.

\begin{abstract}
Baseball is a popular and very lucrative bat-and-ball sport that uses a wooden bat to score runs. We hypothesize that new design features for baseball bats will emerge from their shape optimization using parametric modeling and genetic algorithms. We converge the location of two points on bats made from maple (Acer sp.) and ash (Fraxinus sp.) wood that are associated with increased velocity of a ball rebounding off a bat: vibrational nodal points and the center of percussion (COP). Our modeling and optimization approach was able to reduce the distance between the nodal points and COP from $166.0 \mathrm{~mm}$ to $52.1 \mathrm{~mm}$. This change was similar in both wood species and resulted from changes to the geometry of the bat, specifically shifting of the mass of the bat toward the center of the barrel and removing mass from the very end of the barrel. We conclude that the combination of parametric finite element modeling and optimization using genetic algorithms is a powerful tool for exploring virtual designs for baseball bats that are based on performance criteria and suggest that our designs could be realized in practice using subtractive manufacturing technology.
\end{abstract}

Keywords: baseball bat; wood; maple; ash; shape optimization; finite element modeling; genetic algorithm; modal analysis; nodal point; center of percussion

\section{Introduction}

Baseball is a bat-and-ball sport that is popular in the USA, Canada, Cuba, Dominican Republic, Japan, Korea, Mexico and Venezuela [1]. In the USA in 2017, the revenues in Major League Baseball were estimated to be USD 9.46 billion, and the league is becoming richer due to increased revenue from media contracts [2]. Increased revenues have flowed over to player payments, particularly for players with high batting averages that play decisive roles in winning games. For example, one batter recently secured the largest contract in the history of US sports, which was worth USD 430 million [2], larger than the individual GDPs of several Pacific Island countries [3].

The baseball bat is the key instrument used to score runs. It is a tapered wooden cylinder with a button handle (knob) at the narrow end. This design evolved over the last 150 years by trial and error, incremental innovation and partly by engineering calculations [4-7]. However, bats with more diverse shapes including short, long, flat and banana-shaped bats were experimented with in the nineteenth century. These bats are now prohibited by Rule 3 [8], which states that a baseball bat should be less than 42 inches (1067 $\mathrm{mm})$ long and not more than 2.61 inches $(66.3 \mathrm{~mm})$ in diameter. Rule 3 also stipulates that bats should be made from a single piece of solid wood. This rule has restricted the materials and construction methods used to make bats for Major League Baseball. Hence, bats are now almost exclusively made from sugar maple (Acer saccharum Marshall) (75\%), white ash (Fraxinus americana L.) (20\%) and yellow birch (Betula alleghaniensis Britt) $(5 \%)[9,10]$. Nevertheless, within the aforementioned constraints imposed by Rule 3, there is ongoing innovation by commercial companies to improve the performance of bats and create ones that helps players score runs by hitting the ball harder and with greater rebound velocity. 
The performance of a baseball bat depends on its dimensions and physical properties, the five most important ones being length, diameter, mass and mass distribution and stiffness [11]. The length and diameter of the bat are defined by Rule 3 [8], and the mass and mass distribution depend on the bat geometry and degree of taper from the barrel to the handle [12]. The stiffness depends on the wood's properties, particularly the density, grain angle and anatomical characteristics. Performance can be equated with the power of a bat, as measured by the rebound velocity of a batted ball [11]. The rebound velocity depends on the energy imparted to the ball by the batter's body, arms and wrists, the incoming speed of the ball, the weight of the bat and the point of collision of the ball on the bat [13]. One of these collision points is the center of percussion (COP) [14], defined as the point which, when impacted, provides a minimum reaction force at the axis of the bat's rotation (batsman's hand) [15]. Balls hitting the COP have high rebound velocities, and this location is considered to be the bat's 'sweet spot' $[14,16]$. Another 'sweet spot' which relates to energy imparted to the ball by the player is the location on the bat which, when impacted, minimizes the vibration on the batsman's hands. When a ball hits a bat, flexural vibration occurs, which has a minimum amplitude at the nodal points along the length of the bat (see Figure 1) [17-19]. As the vibrational energy is minimum when the ball hits the nodal points, more energy is transferred back to the ball, and the ball receives the maximum energy. If the nodal points of the flexural modes are close to each other, the amount of excitation of these modes decreases, which results in better bat performance. Designers have attempted to overlay the barrel nodal points of the flexural modes [4]. The positions of the nodal points and COP on a bat (sweet spots) depend on the spatial variation in the mechanical properties of the bat [19-21], and these can be altered by changing the mass distribution of the bat within the constraints of Rule 3, which was mentioned above. Hence, it should be possible to tailor the mechanical properties of a bat at different locations to shift the location of the COP and nodal points as desired and also change the bat's moment of inertia.

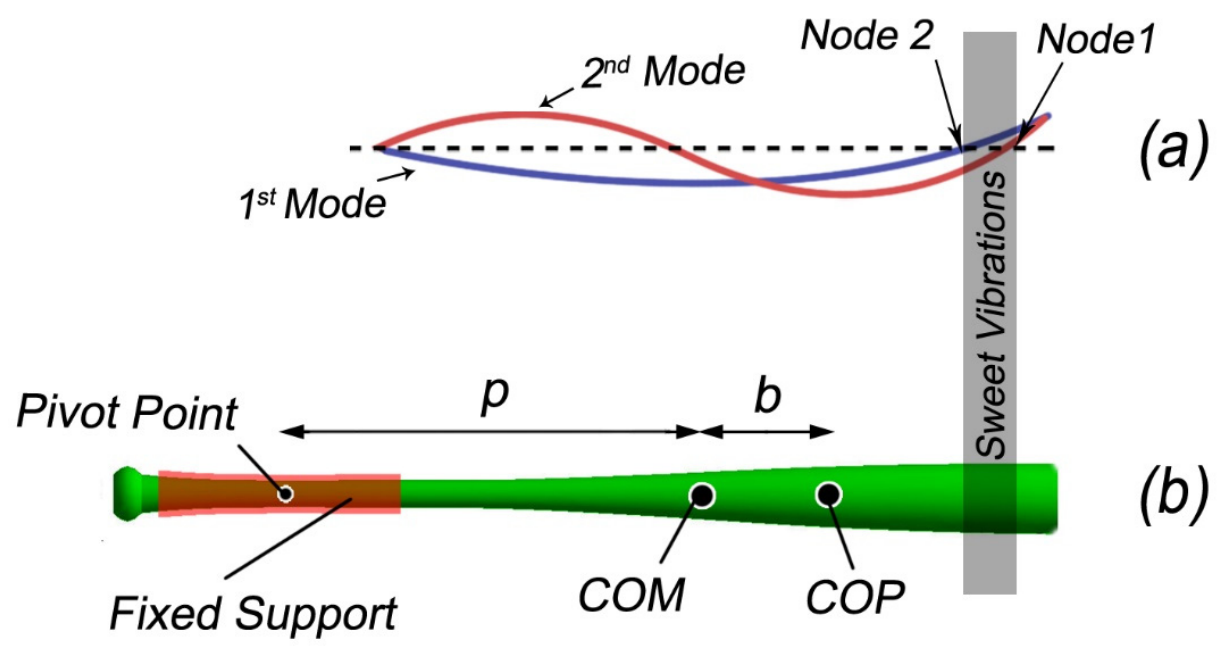

Figure 1. (a) Location of nodal points on a baseball bat. (b) Location of COP on the bat.

Previously, we showed that parametric finite element modeling and optimization algorithms were able optimize the dynamic and vibrational characteristics associated with the improved performance of a cricket bat made from willow (Salix spp.) [22]. We use a similar approach here to optimize the performance of a baseball bat, but our research differs from previous research on cricket bats because here we examine whether the optimal bat geometry is influenced by the wood species (ash vs. maple). In addition, the axis symmetry of baseball bats is different to that of cricket bats as is the complicated performance optimization, which relies on redistributing the mass and mechanical properties of bats, as mentioned above. 
In this paper, we minimize the distances between the nodal points and COP of a baseball bat using parametric modeling and genetic algorithms (GAs). Our research with wooden cricket bats revealed novel design features with the potential to improve the performance of bats [22]. Similarly, we hypothesize that new design features for baseball bats will emerge from their shape optimization using parametric modeling and genetic algorithms (GAs).

\section{Materials and Methods}

The positions of the nodal points and the center of percussion (COP) influence the performance of baseball bats because they alter the location of the sweet spot, as mentioned above.

\subsection{Nodal Points}

Previous research has shown that if a ball hits a bat close to the nodal points, there will be less energy loss due to vibration and therefore greater rebound energy imparted to the ball $[11,18,23-26]$. When a ball strikes a bat at a node point for the first mode, the first mode is not excited at all, but the second mode is generated. Similarly, if the impact point is the node for the second mode, then the second mode is not excited, but the first mode is generated. The further the impact point is from a node, the larger the resulting vibration. Vibrations are weakest, which is desired, when the bat strikes the ball at one of the two node points $[11,18]$. If the nodal points are closer to each other, an impact close to these points will result in less vibration [4]. The location of the nodal points can be altered by tailoring the mass distribution of the bat. The nodal points for a bat when it vibrates via the first and second bending modes are shown in Figure 1. When the ball hits any of these nodal points (node 1 or node 2) or areas close to these points, it will absorb less impact energy, and more energy will be transferred to the ball, increasing the rebound velocity.

\subsection{Center of Percussion}

The center of percussion (COP) is defined as the point on a bat which, when hit by a ball, transmits no force to the batsman's hand, which is considered to be a pivot point $[14,16]$. Figure $1 \mathrm{~b}$ shows the COP and the pivot point on a bat. The pivot point in the figure is in the middle of a fixed support, which is considered to be 6 inches $(150 \mathrm{~mm})$ away from the knob $[11,27,28]$. The location of the COP can be calculated as follows:

$$
b=\frac{I_{y y}}{p M}
$$

where $p$ is the distance between the pivot point and center of mass, $I_{y y}$ is the moment of inertia of the bat about the center of mass and $M$ is the total mass of the bat.

It has been shown previously that when the nodal points and COP on a bat are relatively close, impacts at points near the nodal points and COP will lead to higher ball velocities [29]. We seek to reduce the distances between node 1 , node 2 and the COP (Figure 2), as mentioned in the introduction. The objective function is defined as the root mean square distance (RMSD) between these three points:

$$
R M S D=\sqrt{d_{1}^{2}+d_{2}^{2}+d_{3}^{2}}
$$

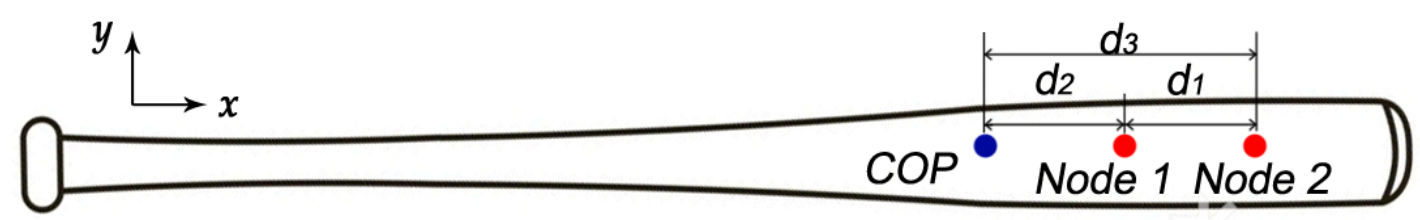

Figure 2. Distances between node 1, node 2 and the COP on the barrel of a baseball bat. 


\subsection{Parametric Design}

The mass distribution and inertial properties of a baseball bat can be tailored by altering its geometry based on 10 parameters which equate to the radius of the bat at different sections and accord with Rule 3 [8].The handle is divided into 5 sections which can have a variable radius at each section, shown as $r_{1}-r_{5}$ in Figure 3. This figure shows a parametric design for a baseball bat as well as a randomly generated baseball bat design. The handle is considered to be symmetrical along the $\mathrm{x}$-axis passing through its center. The barrel, on the other hand, has a hitting side (front) and a non-hitting side (back). The hitting side of the bat is circular. However, the back profile of the bat (non-hitting side) can be altered as shown in Figure 3. This approach is feasible because, in practice, baseball bats made from ash and maple have hitting sides which correspond to the radial and tangential faces of bats. Bats contain stickers on the non-hitting faces, and players are instructed to orientate the stickers vertically (up or down) so that balls only come into contact with either of the hitting faces. Furthermore, one bat on the market has an axe-type handle that restricts bat rotation, creating one hitting and one non-hitting face [30]. Figure 3a shows the top view of our virtual baseball bat. The lower section, which is the hitting side, is a half-cylinder with a constant radius along the barrel that is colored gray in Figure 3a. The radius $\left(r_{6}\right)$ of this half-cylinder is a design variable for the parametric design of the baseball bat. The upper section, on the other hand, can have different radii at different sections, which are denoted by $r_{7}-r_{10}$ in Figure 3a. From the front view, the bat looks like a regular bat with a cylindrical barrel (Figure $3 b$ ). Our approach makes it possible to tailor the mass distribution and the mechanical and bending properties of the bat and ultimately move the nodal points and the COP. Obviously, this approach can lead to a barrel which may or may not have a circular cross-section unlike regular bats; the hitting side will be a half-cylinder, and the other non-hitting side of the barrel can have different radii along the length of the bat.

\subsection{Finite Element Modeling}

Finite element (FE) modeling has been used in the past to investigate the durability of baseball bats, and the models have proven to be valuable tools for understanding the mechanical response of wooden bats during impacts [9,31-33]. In this study, the FE modeling software ANSYS [34] was used to model the baseball bat. A total of 186 solid elements with orthotropic material properties representing the elastic properties of sugar maple and white ash, as listed in Table 1 , were used. The $x$-axis was along the grain direction of the wood, while the $y$ and $z$ directions were along the transverse and radial directions, respectively. A cylindrical fixed support represented the boundary conditions (Figure 4). Elements on the surface of the bat's handle were restrained from moving in any direction as well as rotating about any axis to simulate the bat being held by the batsman. An element size of $10 \mathrm{~mm}$ was selected based on a sensitivity analysis of the effect of the element size on the modal frequencies of the bat. Modal analysis was performed using the block Lanczos solver [35]. As mentioned earlier, the most influential modes are the first and second bending modes of vibration. Figure 5 shows these modes as well as the nodal points.

After performing the modal analysis, the locations of node 1, node 2 and the COP were determined, and the root mean square distance (RMSD) was calculated. 


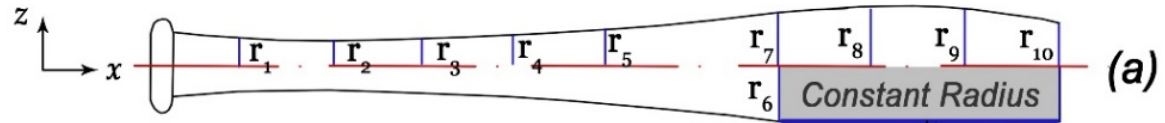

Hitting Side
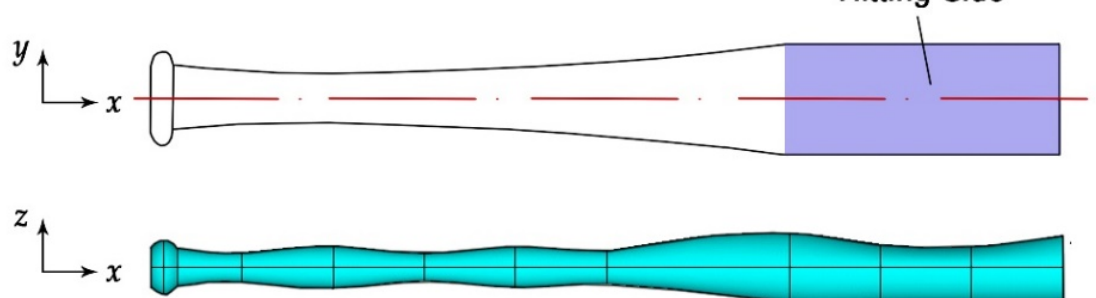

(c)<smiles>[Z]C([Y])C([Y])C</smiles>
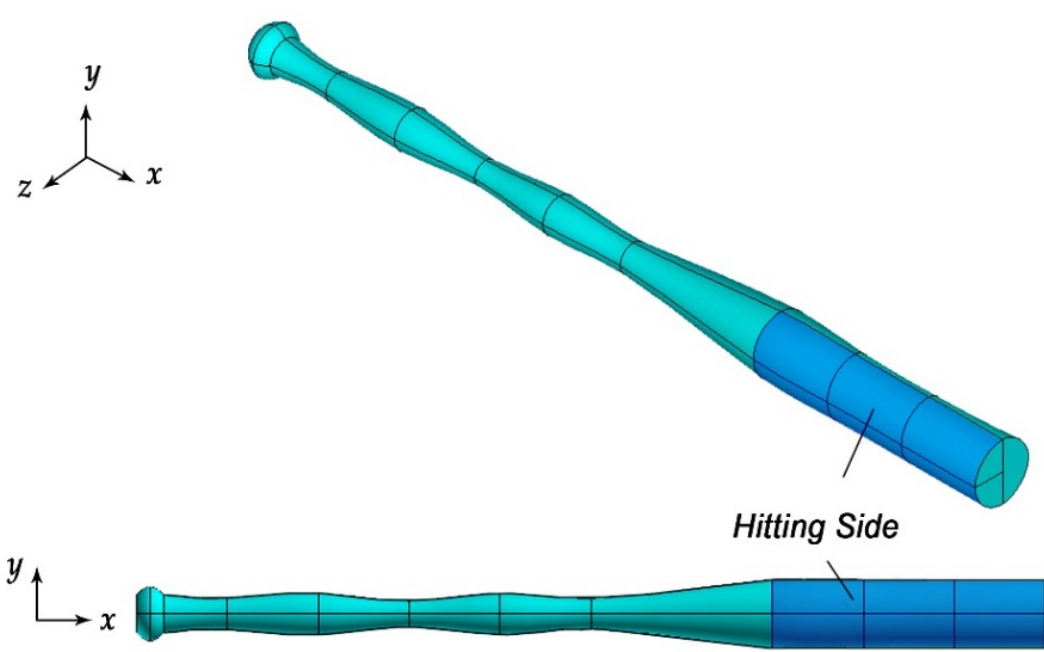

(e)

Figure 3. (a) Parametric design of the baseball bat (top view). (b) Parametric design of the baseball bat (front view). (c) A randomly generated bat design (top view). (d) A randomly generated bat design (isometric view). (e) A randomly generated bat design (front view).

Table 1. Mechanical properties of sugar maple (Acer saccharum Marshall) and white ash (Fraxinus americana L.) [36].

\begin{tabular}{|c|c|c|c|c|c|c|c|c|c|c|}
\hline \multirow{2}{*}{ Wood } & \multirow[t]{2}{*}{ Density $\left(\mathrm{kg} / \mathrm{m}^{3}\right)$} & \multicolumn{3}{|c|}{ Young's Modulus (MPa) } & \multicolumn{3}{|c|}{ Shear Modulus (MPa) } & \multicolumn{3}{|c|}{ Poisson's Ratio } \\
\hline & & $E x$ & $E y$ & $E z$ & $G x y$ & $G x z$ & Gyz & $u y x$ & $u z x$ & $u z y$ \\
\hline Maple & 706 & 12,600 & 820 & 1660 & 760 & 1400 & 12 & 0.037 & 0.07 & 0.35 \\
\hline Ash & 672 & 12,000 & 960 & 1500 & 920 & 1310 & 12 & 0.051 & 0.06 & 0.36 \\
\hline
\end{tabular}

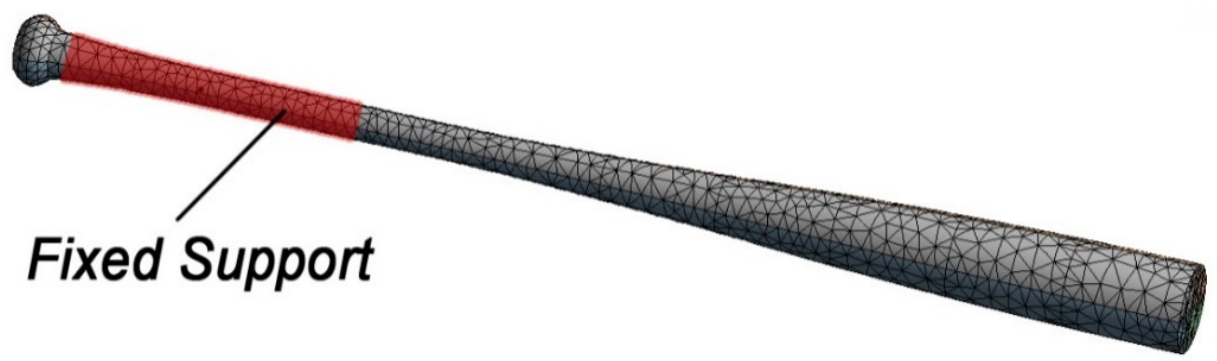

Figure 4. Boundary conditions on the handle of a baseball bat. 

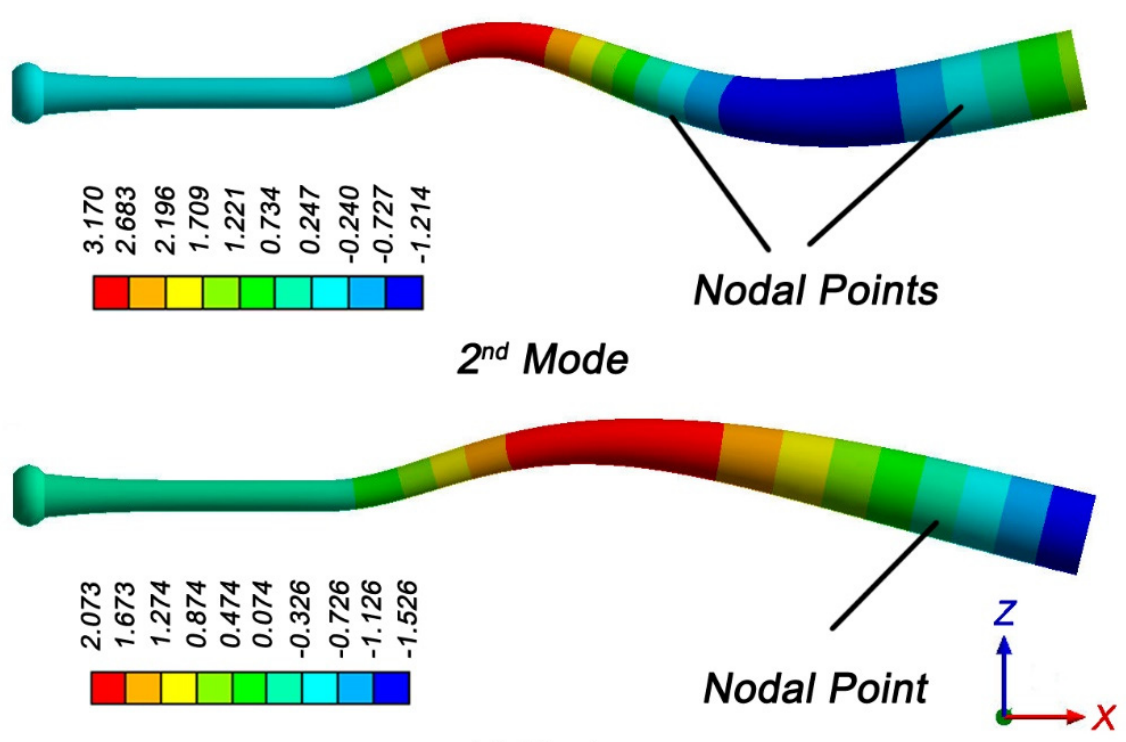

\section{$1^{\text {st }}$ Mode}

Figure 5. Mode shapes of the bat with its nodal points. Note that the nodal points (nodes) are shown in places on the bat in which the displacement is zero.

\section{Optimization of the Performance of the Baseball Bat}

Code was written for the ANSYS software to generate the geometry of the baseball bat, run the modal analysis to determine the location of the nodal points and COP and calculate the objective function. The length of the bat was 34 inches $(864 \mathrm{~mm})$, which is representative of bats used in Major League Baseball [11]. The diameter of the bat should be less than 2.61 inches $(66.3 \mathrm{~mm})$, and therefore, the radius of the bat should be less than $33.2 \mathrm{~mm}$, as dictated by Rule 3 [8]. Hence, the design variables of the problem $\mathrm{r}_{i}$ were restricted between the upper and lower bounds. The lower bounds for the design variables were defined in a way to ensure that the bat could maintain its structural integrity. The allowable maximum radius of the handle at the grip section $\left(r_{1}\right.$ and $\left.r_{2}\right)$ was $20 \mathrm{~mm}$ so that the bat could be held by the batsman. The optimization problem of this study was defined as follows:

Minimize RMSD $\left(r_{i}\right)$, subject to

$$
\begin{gathered}
12 \mathrm{~mm} \leq r_{1}, r_{2}, \leq 20 \mathrm{~mm} \\
12 \mathrm{~mm} \leq r_{3}, r_{4}, r_{5}, r_{6}, r_{7}, r_{8}, r_{9}, r_{10} \leq 33.2 \mathrm{~mm}
\end{gathered}
$$

The genetic algorithm optimization method (GA) was implemented to optimize the geometry of the baseball bat. Genetic algorithms are random adaptive heuristic search algorithms inspired by the process of Darwinian selection. They belong to a larger class of evolutionary algorithms and are designed to find the optimal solution to a problem. The optimization process was performed by integrating the ANSYS script with MATLAB software. Figure 6 shows the optimization flowchart. A custom script in MATLAB stored 10 design variables in a text file called the ANSYS batch file. The ANSYS software read the input design variables, generated the geometry of the baseball bat, meshed the bat and performed the modal analysis. The locations of the nodes and COP were determined, and the objective function (RMSD) was calculated inside the FE script at each iteration and stored in a text file, which served as an input for MATLAB for the next iteration. This loop continued until convergence occurred. MATLAB's GA toolbox was used for this. Sensitivity analysis was performed to determine the population size for the GA, and an initial population size of 100 was used. For better scoping of the feasible design envelope, the first generation of the GA was generated by Latin hypercube sampling (LHS) [37-39]. The root mean square distance (RMSD) was then minimized over 100 generations from the initial LHS design's generated population. During this process, the generational cross-over 
probability and mutation rates were calculated. Crossover is the process of combining two individuals to create new individuals, and the crossover probability is the probability of a selected individual going through a crossover process. Mutation is a random alteration in the value of one or more genes in an individual from its original state. The mutation rate is the probability of each gene being modified. The hardware used for parametric modeling and optimization using GAs was a high-end laptop (Lenovo Ideapad Y700, 17") with an Intel ${ }^{\circledR}$ Core $^{\mathrm{TM}} \mathrm{i7}-6700 \mathrm{HQ}$ CPU at $2.6 \mathrm{GHz}$ and $16 \mathrm{~GB}$ of RAM. Using this computer, each evaluation of the objective function took approximately $8 \mathrm{CPU}$ seconds. The optimization process as a whole took $24 \mathrm{~h}$.

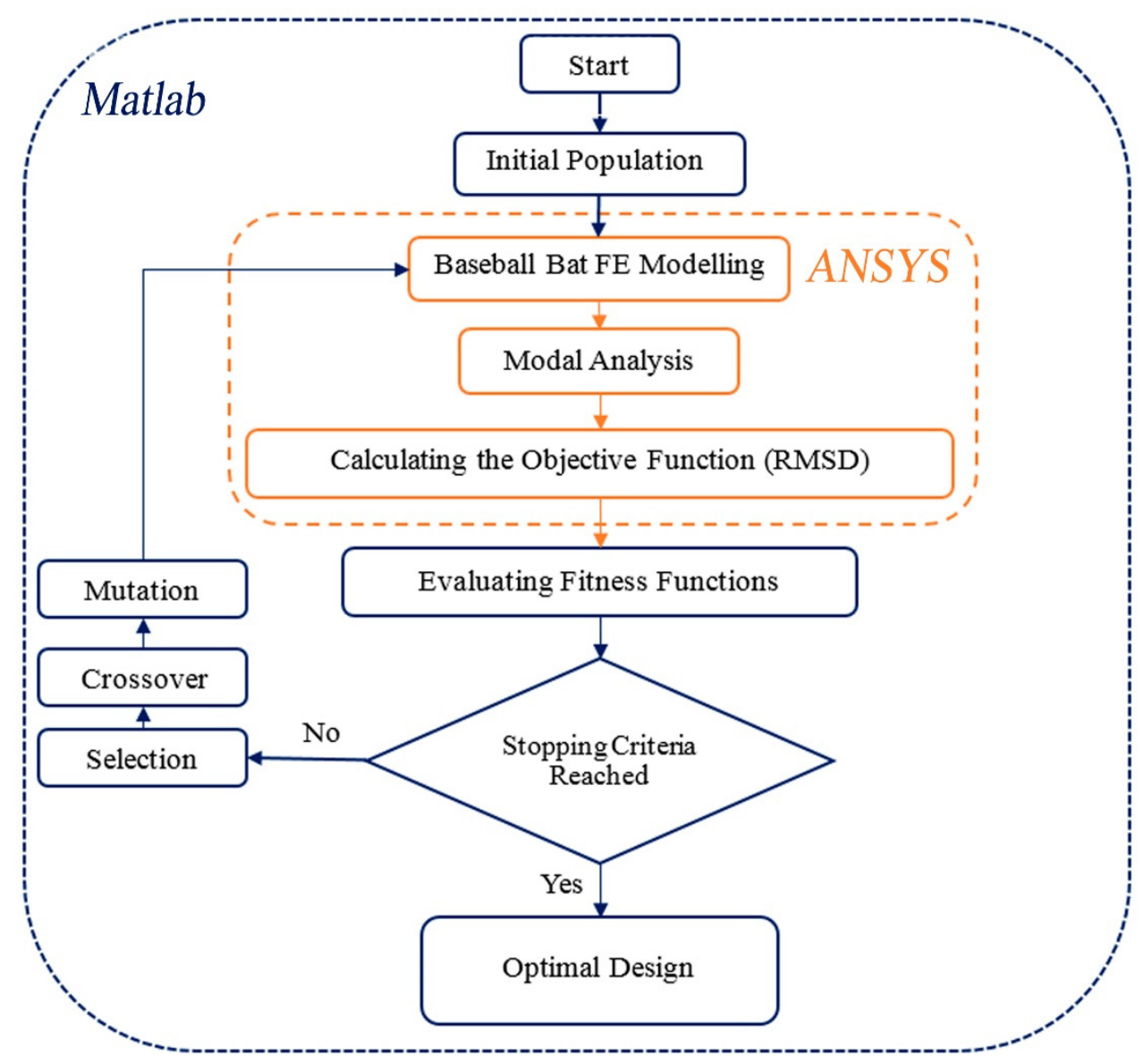

Figure 6. The optimization process flowchart.

The final (optimum) design of the baseball bat was compared to that of one of the best commercial baseball bats: a Rawlings 460 'Big Stick' Professional Model long wood baseball bat (34 inches). The exact dimensions of this bat were obtained by measuring its diameter along the handle and barrel with a digital caliper (Mitutoyo 500-196-30 Digimatic, Mitutoyo, 1-20-1 Sakado Takatsu-ku, Kawasaki, 213-8533, Japan) at multiple points. These diameters were then used as input design variables in the ANSYS software to model the geometry of the 'Big Stick' bat.

\section{Results}

The reduction in the root mean square distance (RMSD) and the resulting change in the geometry of a bat over 100 generations from the initial design generated by Latin hypercube sampling to the endpoint produced by the genetic algorithm (GA) for bats made of white ash and sugar maple are shown in Figures 7 and 8, respectively. The crossover probability was 0.8 , and the mutation rate was 0.2 . For both ash and maple, there was a 
rapid reduction in the RMSD initially, but after the twelfth generation, the reduction in the RMSD as a result of the GA occurred at a lower rate (Figures 7 and 8 ).

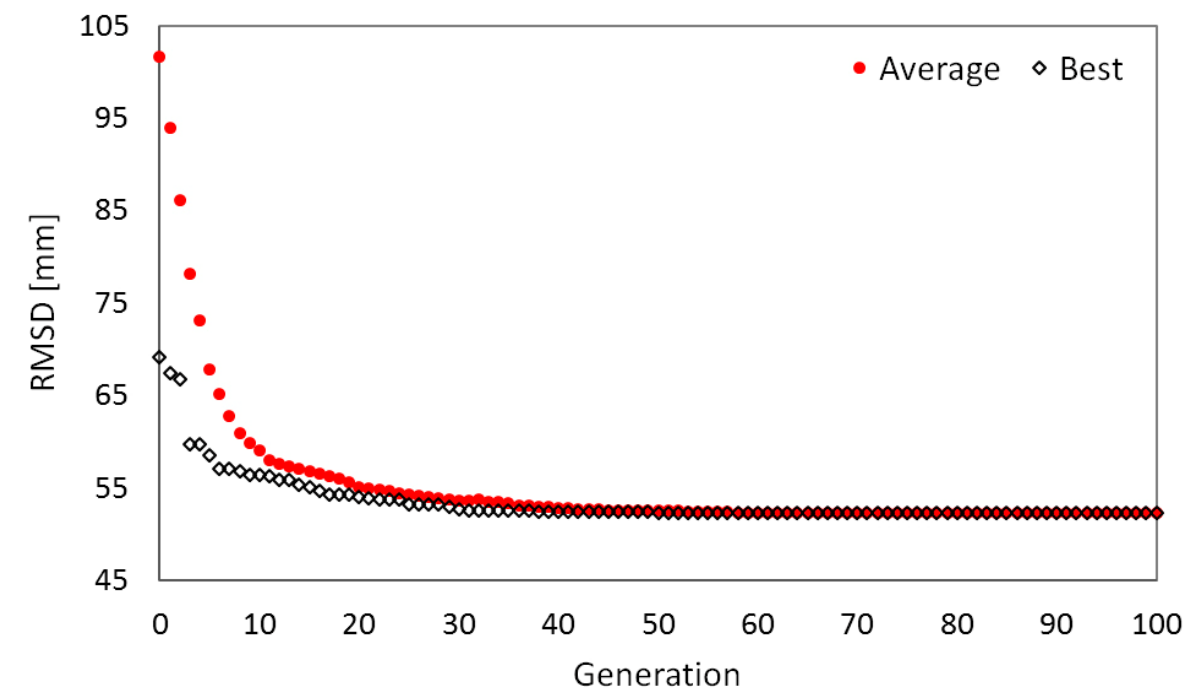

Figure 7. Variation of RMSD with each generation during genetic algorithm optimization for a bat made of white ash.

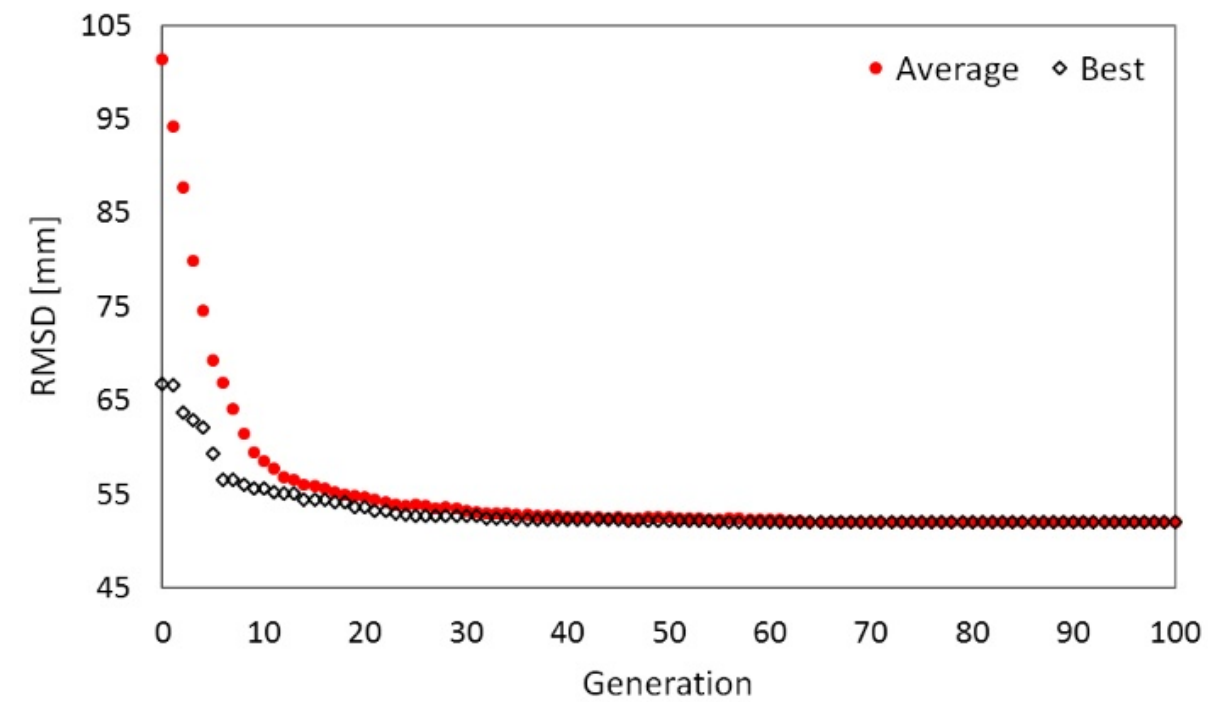

Figure 8. Variation of RMSD with each generation during genetic algorithm optimization for a bat made of sugar maple.

The optimized bats were compared with two designs. The baseline design was a simple cylinder with a fixed diameter of 2.61 inches $(66.3 \mathrm{~mm})$, which is the maximum diameter allowed by Rule 3 [8] (Figure 9a). The diameter of this bat did not change along its longitudinal axis. The second design was that of the Rawlings 460 Big Stick Professional Model (Figure 9b). The exact geometry of the latter bat was obtained as described above. It was modeled in the ANSYS software, meshed, and finally, its objective function (RMSD) was calculated as described above. 
(a)

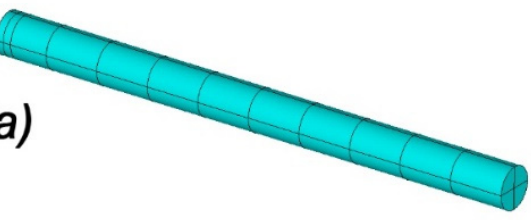

Baseline

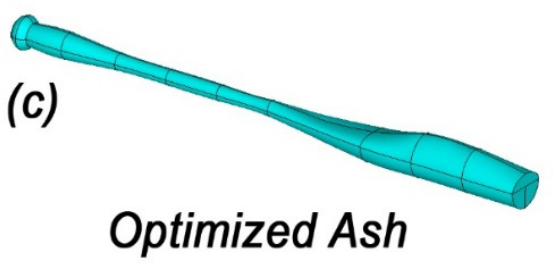

(b)

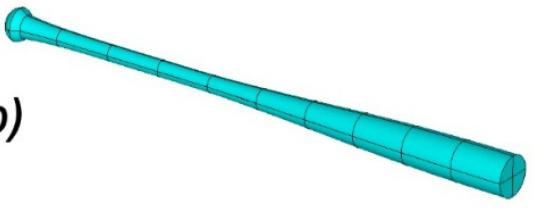

Big Stick

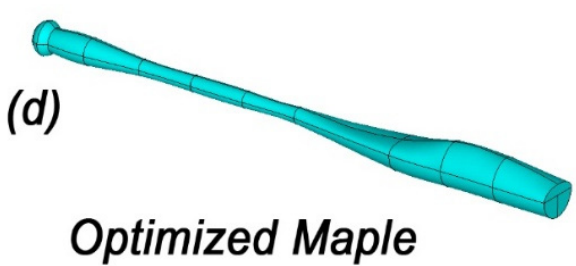

Figure 9. Baseline (a), Big Stick (b) andthe optimized ash (c) and maple (d) baseball bats.

Table 2 shows the design variables, RMSD and the total mass of the baseline, Big Stick and optimized designs for maple and ash. For the bats made of maple, the objective function for the baseline design was $166 \mathrm{~mm}$, and that for the Big Stick bat was $72.29 \mathrm{~mm}$, while for the optimized GA bat, it was $52.13 \mathrm{~mm}$ (a reduction of $27.9 \%$ compared with the Big Stick bat). The total mass of the baseball bat for the baseline design was $2.034 \mathrm{~kg}$ $(71.7 \mathrm{oz})$, and for the Big Stick bat, it was $0.878 \mathrm{~kg}(31 \mathrm{oz})$, while the mass for the GAoptimized bat was $0.933 \mathrm{~kg}$ (32.9 oz). For the bats made of ash, the objective functions were close to those made of maple. The RMSD for the baseline design was $165.9 \mathrm{~mm}$, while for the Big Stick bat made of ash, it was $72.53 \mathrm{~mm}$, which was slightly higher than that of the Big Stick bat made of maple. The RMSD for the optimized bat made of ash was $52.05 \mathrm{~mm}$, which was slightly lower than that of the optimized design for maple, representing a $28.2 \%$ reduction compared with the Big Stick bat made of ash. In general, because sugar maple and white ash have similar mechanical properties (Table 1), there was not going to be a big difference in the design variables for bats made from the two wood species.

Table 2. Optimization parameters for the baseline, GA and hybrid optimized design.

\begin{tabular}{|c|c|c|c|c|c|c|c|c|c|c|c|c|c|}
\hline \multirow{2}{*}{ Design } & \multirow{2}{*}{$\begin{array}{c}\text { Wood } \\
\text { Species }\end{array}$} & \multicolumn{10}{|c|}{ Design Variables (mm) } & \multirow{2}{*}{$\begin{array}{c}\text { RMSD } \\
(\mathrm{mm})\end{array}$} & \multirow{2}{*}{$\begin{array}{c}\text { Mass } \\
(\mathbf{k g})\end{array}$} \\
\hline & & $r_{1}$ & $r_{2}$ & $r_{3}$ & $r_{4}$ & $r_{5}$ & $r_{6}$ & $r_{7}$ & $r_{8}$ & $r_{9}$ & $r_{10}$ & & \\
\hline Baseline & Maple & 33.2 & 33.2 & 33.2 & 33.2 & 33.2 & 33.2 & 33.2 & 33.2 & 33.2 & 33.2 & 166.00 & 2.034 \\
\hline Big Stick & Maple & 13.4 & 12.5 & 12.7 & 13.2 & 16.2 & 20.5 & 25.5 & 29.2 & 31.5 & 32.2 & 72.29 & 0.878 \\
\hline GA Optimized & Maple & 19.9 & 12.1 & 12.0 & 12.2 & 12.1 & 33.1 & 12.2 & 33.0 & 32.5 & 17.0 & 52.13 & 0.931 \\
\hline Baseline & Ash & 33.2 & 33.2 & 33.2 & 33.2 & 33.2 & 33.2 & 33.2 & 33.2 & 33.2 & 33.2 & 165.90 & 1.936 \\
\hline Big Stick & Ash & 13.4 & 12.5 & 12.7 & 13.2 & 16.2 & 20.5 & 25.5 & 29.2 & 31.5 & 32.2 & 72.53 & 0.836 \\
\hline GA Optimized & Ash & 20.0 & 13.0 & 12.0 & 12.0 & 12.0 & 32.4 & 12.1 & 33.1 & 33.1 & 19.7 & 52.05 & 0.873 \\
\hline
\end{tabular}

Figure 9 shows the baseline design, the Big Stick bat and the optimized bats made of maple and ash. In the baseline design, the mass was distributed evenly along the length of the bat. In the Big Stick bat, there was the characteristic taper from the handle to the barrel of the bat, and the mass was relocated toward the end of the bat. In the optimized designs, however, the mass was shifted toward the center of the barrel with the thicker area of the bat around the center of the barrel, and some mass was removed from both ends of the barrel. Removing mass from the end (tip) of the barrel helped to reduce the swing weight. The designs for the optimized bats made of maple and ash were similar. The maple bat was slightly slimmer toward the end of the barrel than the ash bat, but for the other parts of the bat, the dimensions were almost identical. Figure 10 shows the variation in the cross-section of the Big Stick and optimized bats along their lengths. In contrast to commercial bats that have a circular cross-section along the bat, the optimized designs 
had non-circular cross-sections in the barrel section. Some mass was removed from the non-hitting back side of the barrel section of the bat. On the other hand, mass was shifted more toward the hitting area (sweet spot) of the bat. The center of the barrel was thicker, and it had a cross-section which was almost circular. The mass was removed from both ends of the barrel, making its cross-section non-circular at those sections. These optimized designs incorporated features seen in state-of-the-art cricket bats, which are thicker in the sweet spot of the bat and slimmer toward both ends of the blade [22].

\section{Optimized Ash}

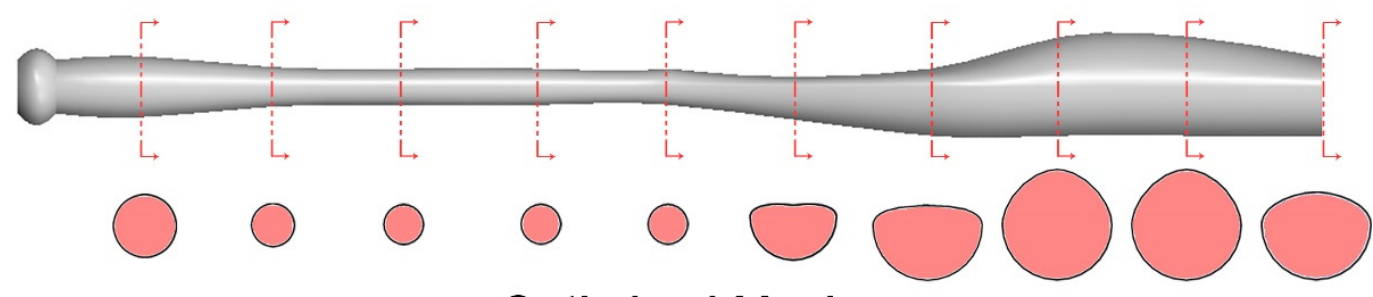

\section{Optimized Maple}

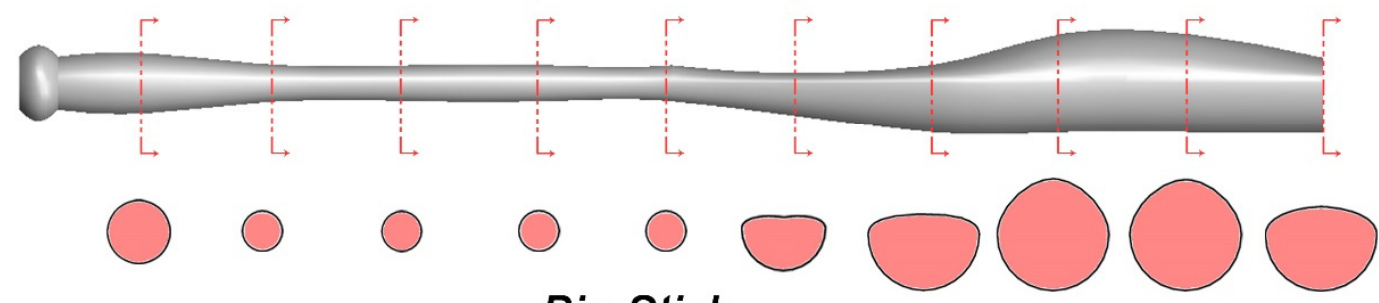

Big Stick

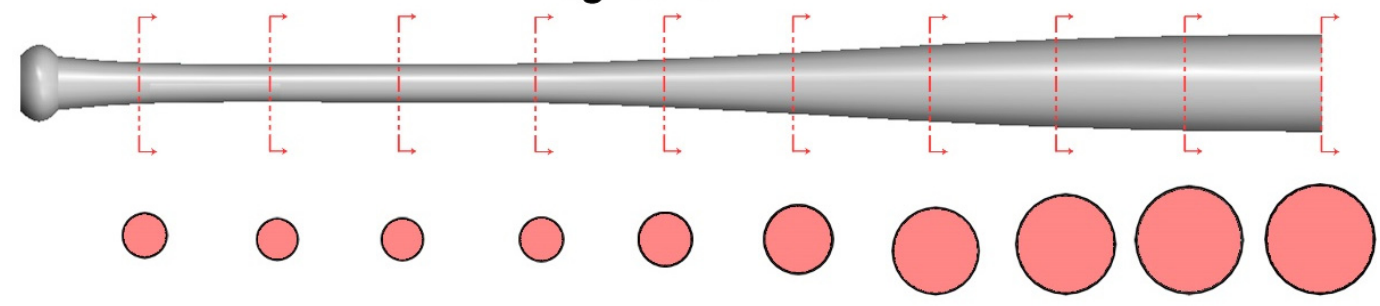

Figure 10. Variation of cross-sections of the bats along their lengths. The cross-sections are below the bats and shown in red.

\section{Discussion}

Our interest in parametric modeling and genetic algorithms was as a tool to reveal new baseball bat designs. To this end, we decomposed the performance of a baseball bat using the simple objective function of converging the nodal points and the center of percussion on a baseball bat. This approach was adopted because previous research on wooden baseball bats and cricket bats had shown that the nodal points and center of percussion influence bat performance $[4,11,14,16-18]$. The final design that emerged from our modeling contained some of the elements seen in contemporary baseball bats, such as tapering of the barrel toward the handle. However, it also revealed new design features, most notably shifting the mass of a bat closer to the sweet spots and a small reduction in mass at the very end (tip) of the bat. The former is also seen in the latest generation of wooden cricket bats [26].

Our approach of using parametric modeling in combination with GA optimization to design a new baseball bat has not been used before, although it has been used to create performance-driven geometries for bats used for cricket and field hockey [22,40], and it potentially could be extended to design wooden bats used in other sports such as hurling. Our algorithmically designed baseball bat used the upper limits for the design variables defined by Rule 3 [8]. Under this rule, the bat could be a simple cylinder with a maximum allowed diameter, but the bat would be far too heavy for optimal performance. 
Interestingly, the weight of the bat that emerged from our modeling ( $32.9 \mathrm{oz}$ or $932.7 \mathrm{~g}$ ) is remarkably similar to the ideal bat weight of $33 \mathrm{oz}(935.5 \mathrm{~g})$ that was derived from coupling physics to force-velocity equations for professional baseball players by Watts and Bahill [13]. Furthermore, the shape of the bat is similar (especially the hitting side of the bat) to that which has evolved largely by trial and error and incremental innovation. Our approach is capable of being extended to perform multi-objective optimization by adding additional criteria to the objective function. Further research is planned to examine the use of vibrational energy loss and possibly durability as objective functions to further optimize the designs of baseball bats.

One limitation of this research is that we did not prototype and test the performance of the new optimized baseball bat. Further studies should perform experimental tests to measure the rebound velocity of balls hitting optimized and traditional bats. Finite element modeling of bat and ball impacts could also be conducted to complement experimental studies. Such modeling could be used to optimize (maximize) the rebound velocity, but high computational capacity would be needed for the modeling because each iteration of the optimization process would involve simulating the impact of a ball on a bat. An additional limitation of our research is that we only investigated the potential effect of a change in the bat geometry on the vibrational characteristics of the sweet spot, and we did not evaluate the effects of such changes on off-sweet-spot characteristics. Research to address this point is needed and could suggest additional design modifications to further improve the performance of baseball bats.

Baseball bats, like cricket bats, are made from a single piece of wood, but the back profiles of cricket bats can be tailored to improve performance. Hence, the back profile of a cricket bat is thickest in the area that is opposite the sweet spot on the flat hitting side of the bat. For baseball bats, however, the same approach is not feasible. As baseball bats are round, a larger diameter in the center of the barrel and smaller diameter toward the end of the barrel would make it difficult to hit the ball properly. However, if the hitting face remains circular, and the back profile is changed, this can be achieved, as we have shown. The resulting design is asymmetric and could not be manufactured using a turning lathe, the machine most commonly used to make baseball bats. Alternatively, multi-axis CNC machines are capable of manufacturing the asymmetric bat designs that emerged from our modeling. In fact, CNC machining is already being employed to manufacture Leinart's patented asymmetric axe-handle baseball bat [30]. Furthermore, the operating instructions for CNC machines can be easily obtained from ANSYS optimization software, which was used here to create virtual prototypes of bats [41]. Therefore, we see no major obstacles to the development of prototypes of 'optimized' bats, which could then be tested for their performance characteristics.

\section{Conclusions}

The combination of parametric modeling and optimization using genetic algorithms was able to reveal new design features, with the potential to improve the performance of baseball bats made from sugar maple and white ash. The bats that emerged from our modeling also shared some of the features seen in modern bats, but the bats were not symmetrical around their long axis. Nevertheless, our designs are capable of being manufactured using multi-axis CNC machines, and therefore, we see no major obstacles to the development and testing of prototypes of 'optimized' bats. We conclude that the modeling approach we have adopted shows promise as a way of creating virtual models of new baseball bat designs and, in principle, wooden bats used in other sports. It is also possible that new design features for baseball bats could emerge from more sophisticated multi-objective modeling. Further research is needed to develop such models and also to prototype and test the new designs that emerged from this study.

Author Contributions: M.S.M. performed all of the modeling. M.S.M. and P.D.E. discussed and commented on the results and wrote and revised versions of the manuscript that led to the one 
that was submitted for publication. Both authors have read and agreed to the published version of the manuscript.

Funding: This research received no external funding.

Informed Consent Statement: Not Applicable.

Data Availability Statement: The data presented in this study are available on request from the corresponding author.

Acknowledgments: P.D.E. thanks Viance, Tolko, FPInnovations, the Faculty of Forestry at UBC and the government of British Columbia for their support of his BC Leadership Chair in Advanced Forest Products Manufacturing Technology at the University of British Columbia (UBC). M.S.M. and P.D.E. thank the Faculty of Forestry at UBC for their financial support of this work, which is part of a program of research for P.D.E.'s BC Leadership Chair.

Conflicts of Interest: The authors declare that they have no affiliations with or involvement with organizations that have financial interests in the subject matter or materials discussed in this paper.

\section{References}

1. Kelly, W. Japan: Professional Baseball Enters the Twenty-First Century. In Baseball Beyond Our Borders; Gmelch, G., Nathan, D.A., Eds.; University of Nebraska Press: Lincoln, Nebraska, 2017; pp. 183-202.

2. Zirin, D. Mike Trout's Mega Deal and Baseball's Economic Rot. Available online: https://www.thenation.com/article/archive/ mike-trout-mlb-players-union-dave-zirin/ (accessed on 18 February 2019).

3. Central Intelligence Agency. The World Factbook. Available online: https://www.cia.gov/library/publications/the-worldfactbook/fields / 208rank.html (accessed on 18 February 2019).

4. Fallon, L.P.; Sherwood, J.A. A study of the barrel constructions of baseball bats. In Proceedings of the 4th International Conference on the Engineering of Sport, Kyoto, Japan, 3-6 September 2002.

5. Noble, L. Inertial and vibrational characteristics of softball and baseball bats: Research and design implications. In Proceedings of the Conference on International Society of Biomechanics in Sports, Konstanz, Germany, 21-25 July 1998; pp. 86-97.

6. Adair, R.K. The physics of baseball. Phys. Today 1995, 48, 26-31. [CrossRef]

7. Drane, P.J.; Sherwood, J.A.; Jones, J.W.; Connelly, T.P. The effect of baseball construction on the game of baseball. In Proceedings of the 7th ISEA Conference, Biarritz, France, 3-6 June 2008; p. 275.

8. Lepperd, T. (Ed.) Official Baseball Rules, 2018 ed.; The Office of the Commissioner of Baseball: New York, NY, USA, 2018.

9. Ruggiero, E.; Sherwood, J.; Drane, P.; Kretschmann, D. An investigation of bat durability by wood species. Procedia Eng. 2012, 34, 427-432. [CrossRef]

10. Bahill, A.T. The Science of Baseball, Modeling Bat-Ball Collisions and the Flight of the Ball; Springer: Berlin, Germany, 2019.

11. Cross, R. Physics of Baseball E Softball; Springer: New York, NY, USA, 2011.

12. Sherwood, J.A.; Ph, D.; Mustone, T.J.; Fallon, L.P. Characterizing the performance of baseball bats using experimental and finite element methods. Sport Eng. 2000, 15, 377-388.

13. Watts, R.G.; Bahill, A.T. Keep Your Eye on the Ball: The Science and Folklore of Baseball; W. H. Freeman and Co.: New York, NY, USA, 1990.

14. Noble, L.; Eck, J. Effects of selected softball bat loading strategies on impact reaction impulse. Med. Sci. Sport. Exerc. 1986, 18, 50-59. [CrossRef]

15. Penrose, J.M.T.; Hose, D.R. An impact analysis of a flexible bat using an iterative solver. J. Sports Sci. 1999, 17, 677-682. [CrossRef]

16. Weyrich, A.S.; Messier, S.P.; Ruhmann, B.S.; Berry, M.J. Effects of bat composition, grip firmness, and impact location on postimpact ball velocity. Med. Sci. Sports Exerc. 1989, 21, 199-205. [CrossRef]

17. Russel, D.A. Acoustics and vibration of baseball and soft ball bats. Acoust. Today 2017, 13, 35-42.

18. Cross, R. The sweet spot of a baseball bat. Am. J. Phys. 1998, 66, 772-779. [CrossRef]

19. Knowles, S.; Brooks, F.; Mather, J.S.B. Novel design of sports equipment through impact vibration analysis. In Proceedings of the 14th Modal Analysis Conference, Dearborn, MI, USA, 12-15 February 1996; pp. 390-396.

20. Noble, L.; Walker, H. Baseball bat inertial and vibrational characteristics and discomfort following ball-bat impacts. J. Appl. Biomech. 1994, 10, 132-144. [CrossRef]

21. Van Zandt, L.L. The dynamical theory of the baseball bat. Am. J. Phys. 1992, 60, 172-181. [CrossRef]

22. Mazloomi, M.S.; Saadatfar, M.; Evans, P.D. Designing cricket bats using parametric modeling and genetic algorithms. Wood Sci. Technol. 2020, 54, 755-768. [CrossRef]

23. Nathan, A.M. Dynamics of the baseball—Bat collision. Am. J. Phys. 2000, 68, 979-990. [CrossRef]

24. Nathan, A.M. Characterizing the performance of baseball bats. Am. J. Phys. 2003, 71, 134-143. [CrossRef]

25. Brooks, R.; Mather, J.S.B.; Knowles, S. The influence of impact vibration modes and frequencies on cricket bat performance. Proc. Inst. Mech. Eng. Part L J. Mater. Des. Appl. 2006, 220, 237-248. [CrossRef]

26. Eftaxiopoulou, T.; Narayanan, A.; Dear, J.P.; Bull, A.M.J. A performance comparison between cricket bat designs. Proc. Inst. Mech. Eng. Part P J. Sport. Eng. Technol. 2012, 226, 16-23. [CrossRef] 
27. Smith, L.V. Evaluating baseball bat performance. Sport. Eng. 2001, 4, 205-214. [CrossRef]

28. Cross, R.; Nathan, A.M. Performance versus moment of inertia of sporting implements. Sport. Technol. 2009, 2, 7-15. [CrossRef]

29. Vedula, G.; Sherwood, J.A. An experimental and finite element study of the relationship amongst the sweet spot, cop and vibration nodes in baseball bats. In Proceedings of the 5th Conference of Engineering of Sport, Davis, CA, USA, 13-16 September 2004; Volume 2, pp. 626-632.

30. Leinert, B.R. Baseball Bat; WO 2009/064798 Al; World Intellectual Property Organization: Geneva, Switzerland, 2009.

31. Ruggiero, E.; Sherwood, J.; Drane, P.; Duffy, M.; Kretschmann, D. Finite element modeling of wood bat profiles for durability. Procedia Eng. 2014, 72, 527-532. [CrossRef]

32. Fortin-smith, J.; Sherwood, J.; Drane, P.; Kretschmann, D. Characterization of maple and ash material properties as a function of wood density for bat/ball impact modeling in LS-DYNA. Procedia Eng. 2016, 147, 413-418. [CrossRef]

33. Fortin-smith, J.; Sherwood, J.; Drane, P.; Kretschmann, D. Characterization of maple and ash material properties for the finite element modeling of wood baseball bats. Appl. Sci. 2018, 8, 2256. [CrossRef]

34. Swanson Analysis System Inc. ANSYS. Academia Research, Release 14; Swanson Analysis System Inc.: Canonsburg, PA, USA, 2014.

35. Fu, Z.-F.; He, J. Modal Analysis, 1st ed.; Butterworth-Heinemann: Oxford, UK, 2001.

36. Ross, R.J. (Ed.) Wood Handbook: Wood as an Engineering Material; U.S. Department of Agriculture, Forest Service, Forest Products Laboratory: Madison, WI, USA, 2010.

37. McKay, M.; Beckman, R.; Conover, W. A Comparison of three methods for selecting values of input variables in the analysis of output from a computer code. Technometrics 1979, 21, 239-245.

38. Mazloomi, M.S.; Ranjbar, M.; Boldrin, L.; Scarpa, F.; Ozada, N. Structural-acoustic optimization of 2-D Gradient Auxetic Sandwich Panels. In Proceedings of the Medyna 2017: 2nd Euro-Mediterranean Conference on Structural Dynamics and Vibroacoustics, Sevilla, Spain, 25-27 April 2017; 2017; pp. 194-199.

39. Mazloomi, M.S.; Ranjbar, M.; Boldrin, L.; Scarpa, F.; Patsias, S.; Ozada, N. Vibroacoustics of 2D gradient auxetic hexagonal honeycomb sandwich panels. Compos. Struct. 2018, 187, 593-603. [CrossRef]

40. McHutchon, M.; Manson, G.; Carre', M. A Fresh Approach to Sports Equipment Design: Evolving Hockey Sticks Using Genetic Algorithms. In The Engineering of Sport 6; Moritz, E.F., Haake, S., Eds.; Springer: New York, NY, USA, 2006.

41. Turrin, M.; Von Buelow, P.; Stouffs, R. Design explorations of Performance driven geometry in architectural design using parametric modeling and genetic algorithms. Adv. Eng. Inform. 2011, 25, 656-675. [CrossRef] 